\title{
Perceived contraindications to thrombolytic treatment in acute myocardial infarction. A survey at a teaching hospital
}

\author{
David S Wald
}

\begin{abstract}
Objective-To examine the use of thrombolytic treatment in acute myocardial infarction when faced with perceived contraindications to treatment and to explore the justification for withholding treatment in such clinical situations.

Methods-Interview survey of all doctors responsible administering thrombolysis to patients with acute myocardial infarction at a teaching hospital in the UK from March to May 1997.
\end{abstract}

Results-20 doctors were interviewed and asked whether they would give or withhold thrombolysis in a series of 19 clinical situations. These included patients presenting with both an acute myocardial infarction and one of the following associated conditions: a confirmed gastrointestinal haemorrhage, a suspected gastrointestinal haemorrhage, a peptic ulcer, an abdominal aortic aneurysm, a recent cerebrovascular accident, a known intracranial aneurysm, a known intracranial tumour, a recent dental extraction, recent surgery, severe hypertension, proliferative diabetic retinopathy, a history of bleeding diathesis, coma, recent cardiopulmonary resuscitation, pregnancy, menstruation, and a recent central venous puncture. In all but one of the clinical situations (definite current gastrointestinal haemorrhage) there was wide variation in response as to what constitutes a contraindication to thrombolytic treatment. Overall, a substantial proportion of doctors (35\%-95\%) would withhold treatment on account of any one of these clinical histories.

Conclusion-Clinicians may be withholding thrombolysis in acute myocardial infarction on account of perceived contraindications for which there is little or no evidence of increased haemorrhagic risk. An effective treatment for acute myocardial infarction is probably being underused.

( Accid Emerg Med 1998;15:329-331)

Keywords: thrombolytic treatment; acute myocardial infarction
Randomised clinical trials have demonstrated that administration of thrombolytic treatment reduces mortality in patients with acute myocardial infarction. ${ }^{12}$ Treatment starting within the first six hours after onset of symptoms is associated with a saving of 30 lives per 1000 patients treated. ${ }^{3}$ None the less concern over the possible complications of treatment has limited the extent to which thrombolysis is used. ${ }^{4}$

There is considerable variation in practice between doctors and hospitals in the use of thrombolysis in the management of acute myocardial infarction. ${ }^{56}$ While most doctors are likely to withhold thrombolytic treatment in certain situations, such as a patient presenting with an acute myocardial infarction and a gastrointestinal haemorrhage, the decision to withhold thrombolysis in some cases is perceived as difficult. There is also a tendency for clinicians to adopt a more conservative approach for fear of causing harm. Such action may limit the use of an effective treatment for a condition with a high mortality. It has already been reported that the presence of an abdominal aortic aneurysm is perceived by many doctors as a reason to forego thrombolysis in acute myocardial infarction. ${ }^{7}$ To examine this issue with respect to other perceived contraindications a survey was conducted at a teaching hospital in the UK, and the results on abdominal aortic aneurysm are included for completeness.

\section{Methods}

All doctors responsible for the early management of acute myocardial infarction were interviewed as to whether they would give or withhold thrombolysis in a series of clinical situations. These included patients presenting with both an acute myocardial infarction and one of the following associated conditions: a confirmed gastrointestinal haemorrhage, a suspected gastrointestinal haemorrhage, a peptic ulcer, an abdominal aortic aneurysm, a recent stroke, a known intracranial aneurysm, a known intracranial tumour, a recent dental extraction, recent surgery, severe hypertension, proliferative diabetic retinopathy, a history of bleeding diathesis, coma, recent cardiopulmonary resuscitation, pregnancy, menstruation, and a recent central venous puncture. Twenty 
Table 1 Response of the 20 doctors interviewed

\begin{tabular}{llll}
\hline & \multicolumn{3}{l}{ Treat with thrombolysis? } \\
\cline { 2 - 4 } Clinical situation & Yes & No (\%) & Don't know \\
\hline Current (confirmed) gastrointestinal haemorrhage & 0 & $20(100)$ \\
Severe hypertension (systolic $>200$, diastolic $>140 \mathrm{~mm} \mathrm{Hg})$ & 1 & $19(95)$ \\
Unconcious patient & 1 & $19(95)$ \\
Known intracranial tumour & 2 & $18(90)$ \\
Suspected (unconfirmed) gastrointestinal haemorrhage & 3 & $17(85)$ \\
Recent major surgery (within 1 week) & 3 & $17(85)$ \\
Subclavian venous puncture & 5 & $15(75)$ \\
Known abdominal aortic aneurysm & 7 & $13(65)$ \\
Bleeding diathesis & 5 & $13(65)$ & 2 \\
Pregnancy & 5 & $13(65)$ & 2 \\
Known peptic ulcer & 8 & $12(60)$ \\
Recent stroke (within 6 months) & 8 & $12(60)$ \\
Known intracranial aneurysm & 7 & $12(60)$ & 1 \\
Peri-infarct cardiopulmonary resuscitation & 9 & $11(55)$ \\
Menstruation & 9 & $11(55)$ \\
Internal jugular vein puncture & 9 & $11(55)$ \\
Proliferative diabetic retinopathy & 10 & $10(50)$ \\
Recent dental extraction (within the last 4 days) & 12 & $8(40)$ \\
Recent minor surgery (within 1 week) & 13 & $7(35)$ & \\
\hline
\end{tabular}

doctors were interviewed and all responded to the survey.

\section{Results}

Table 1 shows the response of the 20 doctors to whether they would use thrombolysis in the 19 specified clinical situations. Only in one (definite current gastrointestinal haemorrhage) is there a clear contraindication and here the decision against the use of thrombolysis was unanimous. In the other clinical situations there is a wide disagreement in opinion as to what constitutes a contraindication to thrombolytic treatment. This disagreement reflects a lack of evidence on the risks and benefits of thrombolytic treatment in these particular cases. Overall, a substantial proportion of doctors $(35 \%-95 \%)$ would withhold treatment on account of any one of these clinical histories.

\section{Discussion}

A major side effect of thrombolytic treatment is bleeding, which has an estimated rate between 0.5 and $1 \%$ in studies that did not use invasive procedures, such as cardiac catheterisation. ${ }^{8}$ The most serious complication is intracerebral bleeding, which occurs with a frequency between 0.2 and $1.6 \%^{29-11}$ and is particularly associated with the use of heparin. ${ }^{12-14}$ In the collaborative overview of the large trials of fibrinolytic treatment versus control, the excess risk of systemic bleeding in the streptokinase/ acetylsalicylic acid group was three per 1000 patients treated and the excess risk of intracerebral haemorrhage was one per 1000 patients treated. These figures compare favourably with the overall saving of 30 lives per 1000 patients treated within six hours of symptom onset. ${ }^{3}$

The exclusion of patients with a history of stroke and of patients with a history of severe hypertension from thrombolytic treatment is based on a small number of patients receiving recombinant tissue plasminogen activator. ${ }^{4}$ Some have suggested avoiding thrombolysis up to six months after a stroke, while others have used a two month limit. ${ }^{415}$ Neither policy is a based on evidence. Similarly, although a history of hypertension is a predictor of intracerebral haemorrhage, there is little evidence that high blood pressure at presentation is a contraindication to thrombolysis. ${ }^{4}$ There is evidence that treating those with a raised blood pressure (systolic $>175 \mathrm{~mm} \mathrm{Hg}$ ) is associated with an improved overall mortality. ${ }^{3}$ In spite of this $95 \%$ of doctors in the survey would withhold treatment in cases of severe hypertension (systolic $>200$, diastolic $>140 \mathrm{~mm}$ $\mathrm{Hg}$ ), itself an important risk for further myocardial infarction.

Published recommendations on other perceived contraindications vary between authors and are based on uncontrolled trials and clinical experience. While the absolute risk in such cases is unknown, isolated case reports of thrombolytic treatment in pregnant and menstruating women $^{16}{ }^{17}$ and in patients who have recently received cardiopulmonary resuscitation or a central venous puncture ${ }^{18}{ }^{19}$ suggest that this risk is likely to be small. A recent report also suggests that a history of proliferative diabetic retinopathy should not be a contraindication to thrombolysis. ${ }^{20}$ While a history of peptic ulcer disease, abdominal aortic aneurysm, or bleeding diathesis pose a theoretical risk of bleeding with thrombolysis, there are few data to support this.

\section{Conclusion}

The decision to institute thrombolysis in acute myocardial infarction is today left largely to junior medical senior house officers and registrars whose practice varies widely. Perceived contraindications to thrombolysis are often based on intuitive fears of causing harm rather than evidence. In order to realise the benefits of thrombolytic treatment in acute myocardial infarction, clinicians should be encouraged to give rather than withhold thrombolysis in circumstances where the risks, although unknown, are likely to be small and far outweighed by the benefit of treatment.

I wish to thank Professor Rory Collins and Professor Nicholas Wald for their valuable help and comments.

1 Gruppo Italiano per lo Studio Streptochinasi nell'Infarto Miocardico (Gissi). Effectiveness of intravenous thromboytic treatment in acute myocardial infarction. Lancet 1986;i:397-402.

2 ISIS-2 (Second International Study of Infarct Survival) Collaborative Group. Randomised trial of intravenous streptokinase, oral aspirin, both or neither among 17187 cases of suspected acute myocardial infarction: ISIS-2. Lancet 1988;ii:349-402.

3 FTT Collaborative Group. Indications for fibrinolytic therapy in suspected acute myocardial infarction: collaborative overview of early mortality and major morbidity results from all randomised trials of more than morbidity results from all randomised tri

4 Gore JM, Sloan M, Price TR, et al. Intracerebral hemorrhage, cerebral infarction and subdural hematoma after acute myocardial infarction and thrombolysis in myocardial infarction study. Thrombolysis in myocardial infarction, phase II, pilot and clinical trial. Circulation 1991;83:448-59.

5 Hood S, Bimie D, Curzio JL, et al. Wide variation in the use of thrombolytic therapy among junior doctors in south and central Scotland. Health Bull (Edinb) 1996;54:131-9.

6 Birkhead JS. Thrombolytic treatment for myocardial infarction: an examination of practice in 39 United Kingdom hospitals. Myocardial infarction audit group. Heart 1997;78:28-33.

7 Wald DS. Thrombolysis after acute myocardial infarction. Lancet 1997; 349:1551.

8 Levine MN, Goldhaber SZ, Califf RM, et al. Hemorrhagic complications of thrombolytic therapy in the treatment of myocardial infarction and venous thromboembolism. Chest 1992;102:364-73S.

9 Wilcox RG, Van der Lippe G, Olsson CG, et al. Trial of tissue plasminogen activator for mortality reduction in acute myocardial infarction: Anglo-Scandinavian study of early myocardial infarction: Anglo-Scandinavian study

10 AIMS Trial Study Group. Long-term effects of intravenous anistreplase in acute myocardial infarction: final report of anistreplase in acute myocardial infarction: 
11 Van der Werf F, Arnold AER. Intravenous tissue plasminogen activater and size of infarct, left ventricular function, and survival in acute myocardial infarction. BMJ 1988;297: $1374-9$.

12 The International Study Group. In-hospital mortality and clinical course of 20891 patients with suspected acute myocardial infarction randomised between alteplase and streptokinase with or without heparin. Lancet 1990;339:

13 ISIS-3 (Third International Study of Infarct Survival) Collaborative Group. ISIS-3: a randomised comparison of streptokinase vs tissue plasminogen activator vs anistreplase and of aspirin plus heparin vs aspirin alone among 41299 cases of suspected acute myocardial infarction. Lancet 1993; 339:753-70.

14 Collins R, Peto R, Baigent C, et al. Aspirin, heparin and fibrinolytic therapy in suspected acute myocardial infarction. N Engl J Med 1997;336:847-60.
15 Thrombolytic therapy in thrombosis: a National Institutes of Health consensus development conference. Ann Intern Med 1980;93:141-4.

16 Sekyema YF, Baltazar RF. Is thrombolytic therapy safe during active menstruation? J Emerg Med 1995;13:345-8.

17 Conti CR. Is menstruation a contraindication to thrombolytic therapy? Clin Cardiol 1992;15:625-6.

18 Cross SJ, Lee HS, Rawles JM, et al. Safety of thrombolysis in associated cardiopulmonary resuscitation. BMJ 1991;303: 1242.

19 Tenaglia AN, Califf RM, Candela RJ, et al. Thrombolytic therapy in patients requiring cardiopulmonary resuscitaion. Am J Cardiol 1991;68:1015-9.

20 Higgs ER, Parfitt VI, Harney BA, et al. Use of thrombolysis for acute myocardial infarction in the presence of diabetic retinopathy in the UK, and associated ocular haemorrhagic complications. Diabet Med 1995;12:426-8.

\section{EMERGENCY CASEBOOK}

\section{Waldenström macroglobulinaemia presenting as bleeding diathesis with paradoxical coagulation of blood samples}

A 79 year old man, who had been well all his life, presented to our accident and emergency department with episodic epistaxis and bleeding gums of two days' duration. On examination there were splinter haemorrhages in every finger. Petechiae were present in the hands and over the shins. Cardiac murmurs consistent with aortic sclerosis and mitral regurgitation were present. The patient was apyrexial. Blood taken by different doctors on three occasions, collected in EDTA and citrate, consistently clotted on reaching the laboratory. On the fourth occasion, blood taken and maintained at body temperature allowed analysis. The following results were obtained: haemoglobin $98 \mathrm{~g} / \mathrm{l}$, mean corpuscular volume $99 \mathrm{fl}$, white cell count $5.7 \times 10^{9} / 1$, platelet count $127 \times 10^{9} / 1$, erythrocyte sedimentation rate $120 \mathrm{~mm} / \mathrm{hour}$, prothrombin time 23 seconds, activated partial thromboplastin time 49 seconds, thrombin time 10 seconds, globulin $56 \mathrm{~g} / 1$, albumin $36 \mathrm{~g} / \mathrm{l}$, and bilirubin $29 \mu \mathrm{mol} / 1$. A provisional diagnosis was made of a lymphoproliferative disorder with possible cold agglutinins. This was confirmed the next day on bone marrow examination as Waldenström's macroglobulinaemia. The bone marrow showed a diffuse increase in lymphoplasmacytoid cells. Immunophenotyping confirmed a monoclonal proliferation of $\operatorname{IgM}(\mathrm{K})$ cells with a paraprotein concentration of $37 \mathrm{~g} / 1$. Abdominal ultrasound confirmed a normal sized liver and spleen. The patient was started on chlorambucil and remains well on regular follow up.

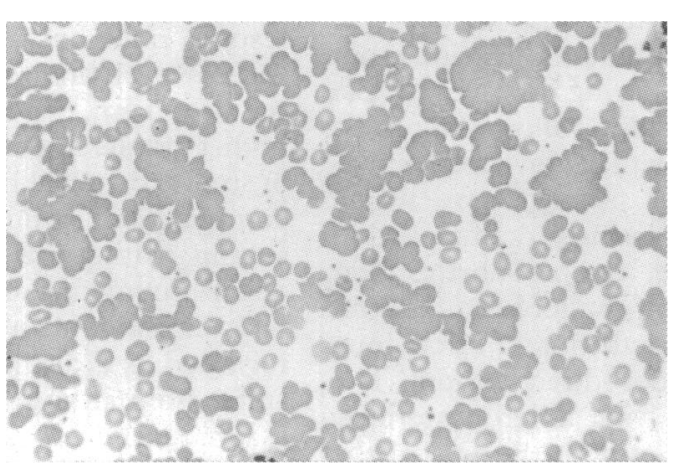

In this case bleeding of gums and epistaxis, with no previous relevant history, needed to be investigated for possible bleeding disorders. Blood samples were taken and sent to the laboratory. When it was realised that blood had clotted on three occasions despite all precautions, a possibility of the presence of cold agglutinins was considered. The fourth sample was kept warm by squeezing the bottle in the hand until it was ready for analysis. Cold agglutination is not a true clotting of blood. The coagulum appears like a homogenous jelly and is distinct from clotted blood as there is no separation of serum and clot (fig 1). This process only occurs at temperatures below $37^{\circ} \mathrm{C}$ and can be reversed by warming the blood. Although the phenomena of cryoglobins causing cold agglutination of blood at temperatures below $37^{\circ} \mathrm{C}$ is well documented, an extensive search of literature has not revealed this phenomena as the first presentation of Waldenström's macroglobulinaemia in an emergency department.

M HARBORD ${ }^{\star}, \mathrm{s}$ IVANOVA, N AKHTAR ${ }^{\star}, \mathrm{Y}$ GUPTA, ${ }^{\star}$ Department of Medicine and Haematology and Department of Accident and Emergency, King George Hospital, Barley Lane, Goodmayes, Essex IG3 $8 Y B$. Correspondence to: Mr Gupta, Consultant in Accident and Emergency. 